\title{
Hot wire configuration for depositing device grade nano-crystalline silicon at high deposition rate.
}

\author{
O. Nos ${ }^{1}, \underline{\text { P.A. Frigeri }}{ }^{1}$, J. Bertomeu ${ }^{1}$. \\ 1. Dept. de Física Aplicada i Òptica, Universitat de Barcelona \\ Barcelona-08028, Spain, Ph: +34934039221 , fax: +34934039219 \\ Email of corresponding author: pfrigeri@ub.edu
}

\begin{abstract}
The University of Barcelona is developing a pilot-scale hot wire chemical vapor deposition (HW-CVD) set up for the deposition of nano-crystalline silicon (nc-Si:H) on $10 \mathrm{~cm} \times 10 \mathrm{~cm}$ glass substrate at high deposition rate. The system manages 12 thin wires of $0.15-0.2 \mathrm{~mm}$ diameter in a very dense configuration. This permits depositing very uniform films, with inhomogeneities lower than $2.5 \%$, at high deposition rate (1.5 $3 \mathrm{~nm} / \mathrm{s})$, and maintaining the substrate temperature relatively low $\left(250^{\circ} \mathrm{C}\right)$. The wire configuration design, based on radicals' diffusion simulation, is exposed and the predicted homogeneity is validated with optical transmission scanning measurements of the deposited samples. Different deposition series were carried out by varying the substrate temperature, the silane to hydrogen dilution and the deposition pressure. By means of Fourier transform infrared spectroscopy (FTIR), the evolution in time of the nc-Si:H vibrational modes was monitored. Particular importance has been given to the study of the material stability against post-deposition oxidation.
\end{abstract}




\section{Keywords}

nc-Si:H; Hot Wire Chemical Vapor Deposition; homogeneity; FTIR, oxidation

\section{Introduction}

The micromorph tandem structure constitutes one of the most promising silicon based technologies for the upgrading of amorphous silicon (a-Si:H) thin film solar cell factories [1]. However, technological issues related with the scalability of this technology up to large areas $\left(>1 \mathrm{~m}^{2}\right)$ still have to be solved. In particular, to make the production of micromorph solar cell economically profitable, the deposition rate $\left(\mathrm{R}_{\mathrm{d}}\right)$ of the intrinsic nanocrystalline silicon (nc-Si:H) layer needs to be increased from 0.2 0.3 $\mathrm{nm} / \mathrm{s}$, typical values for the deposition of the a-Si:H layer [2], to rates higher than 1 $\mathrm{nm} / \mathrm{s}$.

High deposition rates up to $10 \mathrm{~nm} / \mathrm{s}$ [3] can be achieved with the standard plasma enhanced chemical vapor deposition (PE-CVD) technique by combining the so-called high pressure depletion (HPD) regime [4] with the very high frequency (VHF) approach [5]. This combination (HPD-VHF) allows obtaining high quality material which results in high conversion efficiencies of the cell; $\eta=6.3 \%$ for $R_{d}=8 \mathrm{~nm} / \mathrm{s}[6]$ and $\eta=9.1 \%$ for $\mathrm{R}_{\mathrm{d}}=2.3 \mathrm{~nm} / \mathrm{s}$ [7].

However, the aforementioned efficiencies correspond to cells with an effective area around $0.25 \mathrm{~cm}^{2}$. Indeed, depositing high performance nc-Si:H material over large area using the HPD-VHF regime seems to be difficult. Even the standard inhomogeneity of $\pm 5 \%$ [2] can be critical for the performance of the material deposited close to the nc$\mathrm{Si}: \mathrm{H} / \mathrm{a}-\mathrm{Si}: \mathrm{H}$ transition [8,9]. Moreover, the HPD regime is susceptible to form powder 
in the reactor $[9,10]$.

In recent years, hot wire chemical vapor deposition (HW-CVD) has arisen as a promising alternative for the deposition of nc-Si. HW-CVD has the potential to deposit nc-Si:H layers at high deposition rate [11,12] and low deposition pressure (1-20 Pa), without any problems of powder formation. Furthermore, the kinetic of the radicals generated at the hot wire surface and moving towards the substrate is governed exclusively by the diffusion of the different chemical species. No plasma is used to generate the radicals. Thus, the homogeneity of the film is not affected by the standing waves effect, characteristic of the PE-CVD technique $[13,14]$. This makes it easier to scale up the HW-CVD technique to large area without any loss in the film's homogeneity $[15,16]$.

In this paper, we present an appropriate hot wire design for depositing at high deposition rate, very uniform nc-Si:H over an area of $10 \mathrm{~cm} \times 10 \mathrm{~cm}$. The proposed wire configuration could be easily scaled up to larger area.

Growing thick films $(>1.5 \mu \mathrm{m})$ of device grade nc-Si:H material at high deposition rate seems to imply an additional problem: the parameter window which allows obtaining dense stable material becomes very narrow, at least for PE-CVD [17]. Recently, the infrared analysis has been proven as an efficient tool for the optimization of the material grown with the PE-CVD technique at a deposition rate of $2 \mathrm{~nm} / \mathrm{s}$ [18]. Best cell efficiencies are obtained when the nc-Si:H films do not show any post deposition oxidation. In this paper, the same strategy has been used for the preliminary optimization of the material obtained with our HW-CVD configuration. 


\section{Experimental}

The net configuration of the HW-CVD system was designed in order to obtain high deposition rates and assure high uniformity over a deposition area of $10 \mathrm{~cm} \times 10 \mathrm{~cm}$. To optimize the uniformity of the film, the thickness profile $d(x, y)$ was calculated supposing it to be proportional to the total radical flow $\vec{J}(\vec{x})$ reaching the substrate at the point $\vec{x}=(x, y, 0)$ during the stationary regime of the deposition, i.e. $d \alpha J_{z}(x, y, 0)$. The radicals are generated at the wires surface with a generation rate $\rho(\vec{x})=\partial c(\vec{x}) / \partial t$, where $c(\vec{x})$ is the total radicals' concentration, considered to be the same for each wire but with an unknown magnitude. Thus, the radicals' flow $\vec{J}(\vec{x})=D \vec{\nabla} c(\vec{x})$ can be determined up to a multiplicative constant by solving the diffusion equation,

$$
\Delta c(\vec{x})=\frac{\rho(\vec{x})}{D} \text { for } \vec{x} \in S
$$

subjected to Milne type boundary conditions. More details on the definition of the problem are given elsewhere [19]. Here the domain of definition $S$ is a parallelepiped with the substrate occupying its face lying in the $(x, y)$ plane. This approach allowed determining the profile of the deposited film $d(x, y)$ up to a multiplicative constant without modelling any chemistry involved in the process.

The resulting optimized configuration of the pilot-scale hot-wire prototype consists of 12 parallel wires of about $20 \mathrm{~cm}$ length, separated $d_{f-f}=16 \mathrm{~mm}$ from each other. The optimal filament to substrate distance was found to be $d_{f-s}=18 \mathrm{~mm}$ [19]. The term pilotscale is used here to remark the fact that the developed prototype is implementing solutions to preserve the filaments from silicide formation and maintain their geometry in spite of the effects of thermal expansion [20], while it could be scaled up to large area 
$\left(>1 \mathrm{~m}^{2}\right)$ without any relevant modification. The radiated power onto the substrate is limited to less than $1 \mathrm{~W} / \mathrm{cm}^{2}$ by using thin tungsten $0.175 \mathrm{~mm}$ diameter wires, heated up to a temperature of about $1850{ }^{\circ} \mathrm{C}$, which was estimated from resistivity measurement. The lowest stationary substrate temperature was found to be about $255{ }^{\circ} \mathrm{C}$ measured using a thermocouple in direct contact with the substrate. Such low substrate temperature is reached without any kind of substrate cooling. Otherwise, the part of the heat radiation coming from the filaments which is transmitted through the substrate is avoided to be reflected back thus keeping the substrate temperature relatively low. Some samples were deposited at a higher temperature of $340^{\circ} \mathrm{C}$. In this case, a metal back plate was placed onto the substrate in order to reflect back the outcoming heat radiation.

The experimental measurements of the thickness profile were optically performed using the Swanepoel envelope method [21] applied to transmission measurements. An $\mathrm{X}-\mathrm{Y}$ table was used to scan the samples with $1 \mathrm{~mm}$ step between measurements, while an Ocean Optics USB2000 spectrophotometer, covering the visible spectrum, was used, via optical fiber, to collect the transmission signal. The experimental set up was controlled and the data were analyzed with homemade software.

The optimization of the nc-Si:H material was done depositing four different series of material varying the silane concentration $[\mathrm{SiH} 4] /([\mathrm{SiH} 4]+[\mathrm{H} 2])$ from $5 \%$ to $10 \%$ with a total gas flow $\Phi_{\mathrm{tot}}=[\mathrm{SiH} 4]+[\mathrm{H} 2]=300 \mathrm{sccm}$. The material close to the nanocrystallineamorphous transition was identified by means of the Raman crystallinity factor $\left(X_{\mathrm{c}}\right)$ of the samples. The Raman shift spectrum was deconvoluted into three Gaussian peaks at $520 \mathrm{~cm}^{-1}$ and $500 \mathrm{~cm}^{-1}$, assigned to the crystalline fraction, and another peak at $480 \mathrm{~cm}^{-1}$ related with the amorphous phase. $X_{\mathrm{c}}$ was defined by the following peak intensity 
relation: $X_{\mathrm{c}}=I_{520}+I_{500} /\left(I_{520}+I_{500}+I_{480}\right)$ [22]. The stability of the material against postdeposition oxidation was studied for samples deposited on single side polished crystalline silicon wafer pieces. The FTIR transmission measurements were carried out using a Bomen DA3 Fourier transform infrared spectrometer at $1 \mathrm{~cm}^{-1}$ wavelength resolution.

\section{Results and Discussion}

\subsection{Homogeneity}

The theoretical prediction of the normalized thickness profile, $d(x, y) / \max [d(x, y)]$, obtained by solving the diffusion problem, Eq.1, is shown in Fig.1. The 12 wires are parallel to the Y-axis and the domain of definition of the problem is defined by a box of $20 \mathrm{~cm} \times 20 \mathrm{~cm} \times 3.6 \mathrm{~cm}$. The normalized thickness shows only very small variations on the central $10 \mathrm{~cm} \times 10 \mathrm{~cm}$ area (enclosed in the figure by a dashed line), which is the area of interest where the substrate will be placed. The predicted inhomogeneity for that area is about $\pm 2.5 \%[23]$.

The chosen filament to substrate distance $\left(d_{f-s}=18 \mathrm{~mm}\right)$ is considered to be the optimal one, corresponding to the shorter distance for which the radical flow, far away from the boundary, propagates as a flat front. This distance clearly depends on the filament-to-filament distance which, in our case, measures $d_{f-f}=16 \mathrm{~mm}$. The optimal $d_{f-s}$ also guarantees that the boundary layer effect affects only the smallest portion of the deposition area. This affected area is identified in Fig.1 with a frame of $d_{\text {cont }}=5 \mathrm{~cm}$ width located between the central $10 \mathrm{~cm} \times 10 \mathrm{~cm}$ area and the $20 \mathrm{~cm} \times 20 \mathrm{~cm}$ contour of the box. 
This simulation model applied to a scaled filaments' net up to larger area deposition $\left(>1 \mathrm{~m}^{2}\right)$ showed that $d_{f-s}$ and $d_{c o n t}$ are not affected by the scaling up as far as $d_{f-f}$ is unchanged. Furthermore, the simulated radical flow reaching the deposition area does not significantly change $(<2 \%)$ when the system is enlarged. For these reasons, it can be assumed that the deposition area of the prototype is beyond the large area deposition limit, defined as the limit whenever a further increment of the catalytic net area (not to be confused with the area of the catalyzer) does not affect the properties of the deposited film.

Fig. 2 shows the experimentally measured normalized thickness map of a nc-Si:H deposition effectuated over a $20 \mathrm{~cm} \times 20 \mathrm{~cm}$ glass. Its comparison with Fig. 1 shows that the inhomogeneities affecting the area of interest of $10 \mathrm{~cm} \times 10 \mathrm{~cm}$ (dashed lines) $( \pm 2.5 \%)$ coincide with the theoretical one. Only inside the area of interest, the profiles are slightly different $(<1 \%)$. These small differences are probably due to inhomogeneities of the substrate temperature, or to differences in each wire temperature, which may have their origin in contact resistance variations. In the later case, the scaling up to longer wires, considering the minor contribution of the contact resistance, should improve the experimental homogeneity. In any case, the theoretical prediction and the experimental measurement of the thickness homogeneity match up well.

\subsection{Deposition rate}

The deposited nc-Si:H used for the preliminary optimization of the material belongs to four different series of material obtained by varying the silane concentration around the nanocristalline-amorphous transition. All the samples have been deposited with a 
silane mass flow high enough to avoid working in the depletion regime. A rough estimation of the silane consumption, based on the deposition rate and deposition area, results in an utilization of about $60( \pm 5) \%$ of the gas for all the deposition conditions, as long as the total gas flow is kept constant $\left(\Phi_{\text {tot }}=300 \mathrm{sccm}\right)$. Fig. 3 shows the deposition rate $R_{\mathrm{d}}$ as a function of the Raman crystallinity factor $X_{\mathrm{c}}$, Three series were deposited at the same substrate temperature of $T_{\mathrm{S}}=255^{\circ} \mathrm{C}$ but varying the deposition pressure $P$ from 0.1 mbar to 0.2 mbar. The last series was deposited at $P=0.1$ mbar but at higher temperature, $T_{\mathrm{S}}=340{ }^{\circ} \mathrm{C}$. The figure shows that an increment of the substrate temperature $T_{\mathrm{S}}$ or the deposition pressure $P$, generally leads to higher deposition rates. The deposition rates vary from $1.4 \mathrm{~nm} / \mathrm{s}$ for highly crystalline samples up to $2.6 \mathrm{~nm} / \mathrm{s}$ for purely amorphous material. As it can be seen in Fig. 3, the average $R_{\mathrm{d}}$ for nc-Si:H close to the crystalline transition $\left(X_{\mathrm{c}} \approx 0.3 \sim 0.5\right)$ is about $2( \pm 0.2) \mathrm{nm} / \mathrm{s}$. These deposition rates are considerably higher than those current $R_{\mathrm{d}}(0.2-0.3 \mathrm{~nm} / \mathrm{s})$ reachable with industrial large area deposition PE-CVD equipment, [2]. On the other hand, they are still considerably smaller than those $R_{\mathrm{d}}$ values reachable by working in the HPD-VHF regime $(10 \mathrm{~nm} / \mathrm{s})$, though, this latter regime of PE-CVD technique is nowadays limitated to small area [3].

\subsection{Material optimization}

The preliminary nc-Si:H optimization has been done following the FTIR hydride stretching mode (SM) signature proposed by Smets et al. [18]. The monitoring in time of the film's IR spectra permits to observe the progression of the post-deposition oxidation processes affecting the samples. This progression is evidenced by the increment in time of the $950-1200 \mathrm{~cm}^{-1} \mathrm{O}-\mathrm{Si}-\mathrm{O} \mathrm{SM}$ and the less prominent $2250 \mathrm{~cm}^{-1}$ $\left(\mathrm{O}_{\mathrm{y}} \mathrm{SiH}_{\mathrm{x}}\right) \mathrm{SM}$ contributions. Smets et al. demonstrated that the presence/absence of the 
narrow high stretching modes (NHSMs) located at $2083 \mathrm{~cm}^{-1}$ and $2103 \mathrm{~cm}^{-1}$, related to the existence of hydrogen platelets on the crystalline grain boundaries surface [18], is correlated with the instability/stability of the material against post-deposition oxidation. This seems to indicate that the progressive oxidation of nc-Si:H samples is due to the replacement of the hydrogen located in the grain boundaries by oxygen.

Fig. 4 shows the FTIR spectra of a nc-Si:H sample close to the crystalline transition for each of the four deposition series. FTIR measurements were carried out for each sample, as deposited and after 12 days of air exposure. The spectra depict the dihydride bending modes $\left(=\mathrm{SiH}_{2}\right)$ at $840-890 \mathrm{~cm}^{-1}$, the $950-1200 \mathrm{~cm}^{-1} \mathrm{O}-\mathrm{Si}-\mathrm{O} \mathrm{SM}$, the $\left(\mathrm{Si}-\mathrm{H}_{\mathrm{x}}\right)$ SMs at $1850-2200 \mathrm{~cm}^{-1}$ and the $\left(\mathrm{O}_{\mathrm{y}} \mathrm{SiH}_{\mathrm{x}}\right) \mathrm{SM}$ at $2250 \mathrm{~cm}^{-1}$.

For all the samples, the contribution of the O-Si-O SM and $\mathrm{O}_{\mathrm{y}} \mathrm{SiH}_{\mathrm{x}} \mathrm{SM}$ is increasing with time. Validating the correlation reported by Smets et al. [18], it can be seen that the NHSMs at $2083 \mathrm{~cm}^{-1}$ and $2103 \mathrm{~cm}^{-1}$ were also present in all the spectra. However, it is clear that for the samples deposited at $P=0.1 \mathrm{mbar}$ and $T_{\mathrm{S}}=255^{\circ} \mathrm{C}$ the post-deposition oxidation is considerably lower than for the others. Not only the increment of the O-Si$\mathrm{O} \mathrm{SM}$ and $\mathrm{O}_{\mathrm{y}} \mathrm{SiH}_{\mathrm{x}} \mathrm{SM}$ is much more moderate, but also the contribution of the NHSMs is much lower. Their behavior with time is similar to the behavior of material obtained using HPD-VHF PECVD, which, when integrated in PIN devices, led to intermediate conversion efficiency [18].

However, the material still needs to be improved. Indeed, previously reported high quality nc-Si:H films, grown with HW-CVD at lower deposition rates $(0.2-0.5 \mathrm{~nm} / \mathrm{s})$, show a Si-H stretching vibration at $2000 \mathrm{~cm}^{-1}$ with a minimal contibution of the 2100 
$\mathrm{cm}^{-1}$ peak [24,25]. Due to the fact that the deposition parameter window may become very narrow at our deposition rate, a further enhancement of the quality material is surely achievable by a refinement of the deposition parameters.

\section{Conclusion}

In this paper, some results have been reported regarding the performance of a pilotscale HW-CVD set up developed at the University of Barcelona. The choice of building a dense net of thin wires enables depositing very uniform nc-Si:H, with an inhomogeneity lower than $\pm 2.5 \%$ at very high deposition rate. The proximity of the wires to the substrate makes that only a small part of the net area, represented by a frame of $5 \mathrm{~cm}$ width, is lost as deposition area due to thickness inhomogeneity larger than $2.5 \%$.

The deposition of different series of $\mathrm{nc}-\mathrm{Si}: \mathrm{H}$ close to the crystalline transition $\left(X_{\mathrm{c}} \approx\right.$ $0.3 \sim 0.5)$ led to an average deposition rate $R_{\mathrm{d}}$ of about $2( \pm 0.2) \mathrm{nm} / \mathrm{s}$ for a wide range of deposition conditions $\left(P=0.1-0.2 \mathrm{mbar}, T \mathrm{~s}=255-340^{\circ} \mathrm{C}\right)$. Regarding large area deposition systems, these $R_{\mathrm{d}}$ values are very interesting given that the current standard deposition rates are much smaller $0.2-0.3 \mathrm{~nm} / \mathrm{s}[2]$.

The material quality has been indirectly evaluated by monitoring the progression of the post-deposition oxidation processes affecting the samples by means of FTIR spectroscopy. The IR spectrum signature is similar to that obtained for HPD-VHF PECVD material, which when integrated in PIN devices led to intermediate cell conversion efficiency [18]. 
These first results are encouraging. However, a further refinement of the deposition parameters is needed to proof the existence of a parameter window for depositing thick stable nc-Si:H films at high deposition rate.

\section{Acknowledgements}

This research has been supported by the Spanish Ministerio de Ciencia e Innovación and the European Regional Development Fund through the projects CLASICO (ENE2007-67742-C04-03) and MICROSIL08 (PSE-120000-2008-001).

\section{References}

1. H. Keppner, J. Meier, P. Torres, D. Fischer, A. Shah. Appl. Phys. A: Mater. Sci. Process. 69 (1999) 169.

2 D. Richard, Photon International, 11-2009, 190.

3 C. Niikura, M. Kondo, A. Matsuda. J. Non-Cryst Solids 338-340 (2004) 42.

$4 \quad$ M. Kondo. Sol. Energy Mater. Sol. Cells 78 (2003) 543.

5 U. Kroll, A. Shah, H. Keppner, J. Meier, P. Torres, and D. Fisher. Sol. Energy Mater. Sol. Cells 48 (1997) 343.

6 Y. Sobajima, M. Nishino, T. Fukumori, M. Kurihara, T. Higuchi, S. Nakano, T. Toyama and H. Okamoto. Sol. Energy Mater. Sol. Cells 93 (2009) 980.

7 T. Matsui, A. Matsuda, and M. Kondo. Sol. Energy Mater. Sol. Cells 90 (2006) 3199.

8 L. Li, Y.M. Li , J.A. Anna Selvan, A.E. Delahoy, and R.A. Levy. J. Non-Cryst. Solids 347 (2004) 106.

9 B. Rech, T. Roschek, T. Repmann, J. Muller, R. Schmitz, and W. Appenzeller. 
Thin Solid Films 427 (2003) 157.

10 A.V. Shah, J. Meier, E. Vallat-Sauvain, N. Wyrsch, U. Kroll, C. Droz, U. Graf. Sol. Energy Mater. Sol. Cells 78 (2003) 469.

11 J. Cifre, J. Bertomeu, J. Puigdollers, M. Polo, J. Andreu, and A. Lloret. Appl. Phys. A: Mater. Sci. Process. 59 (1994) 645.

12 R.E.I. Schropp, Y. Xu, E. Iwaniczko, G.A. Zaharias, and A.H. Mahan. Mater. Res. Soc. Symp. Proc. 715 (2002) A26.3.

13 M.A. Lieberman, J.P. Booth, P Chabert, JM Rax, MM Turner. Plasma Sources Science and Technology 11 (2002) 283.

14 L. Sansonnens, A. Pletzer, D. Magni, A.A. Howling, C. Hollenstein, J.P.M Schmitt. Plasma Sources Science and Technology 6 (1997) 170.

15 K. Ishibashi, M. Karasawa, G. Xu, N. Yokokawa, I. Manabu, A. Masuda, and H. Matsumura. Thin Solid Films 430 (2003) 58.

16 A. Ledermann, U. Weber, C. Mukherjee, B. Schroeder. Thin Solid Films 395 (2001) 61.

17 R.W. Collins, A.S. Ferlauto, G.M. Ferreira, Chi Chen, Joohyun Koh, R.J. Koval, Yeeheng Lee, J.M. Pearce, C.R. Wronski. Sol. Energy Mater. Sol. Cells 78 (2003) 143.

18 A.H.M. Smets, T. Matsui, M. Kondo. J. Appl. Phys. 104 (2008) 034508.

19 P.A. Frigeri, O. Nos, J.D. Calvo, P. Carreras, R. Roldan, A. Antony, J.M. Asensi, J. Bertomeu. Phys. Status Solidi C 7 (2010) 588.

20 P.A. Frigeri, O. Nos, S. Bengoechea, C. Frevert, J.M. Asensi, J. Bertomeu. Thin Solid Films 517-12 (2009) 3427-3430.

21 R. Swanepoel, J. Phys. E 16 (1983) 1215. 
22 C. Droz, E. Vallat-Sauvain, J. Bailat, L. Feitknecht, J. Meier, X. Niquille, A. Shah. Proceedings of Third World Conference on Photovoltaic Energy Conversion, Osaka, (2003) 1544.

23 Previous simulation of the thickness homogeneity, published in [19], let to the belief that the theoretical inhomogeneities affecting the area of interest were only $\pm 1 \%$. This was due to the limited number of mirror images taken into account for the evaluation of the solution of Eq.1. But, an evaluation of the infinite series of mirror images involved in the solution presented in this paper, see Fig.1, led to a worsening of the inhomogeneity up to $\pm 2.5 \%$. This result matches better with the experimental measurement presented in Fig.2.

24 J.K. Rath, R.E.I. Schropp. Mater. Res. Soc. Symp. Proc. 609 (2001) A22.1.

25 S. Klein, F. Finger, R. Carius, M. Stutzmann. J. Appl. Phys. 98 (2005) 024905. 


\section{Figure Captions}

Fig. 1 Normalized thickness profile predicted by the model based on radicals' diffusion. The thick continuous line delimitates the area where the thickness inhomogeneities are lower than $\pm 2.5 \%$, while the dashed line encloses the $10 \mathrm{~cm} \times 10 \mathrm{~cm}$ substrate area.

Fig. 2 Experimentally measured normalized thickness profile of a nc-Si:H sample. The thick continuous line delimitates the area where the thickness inhomogeneities are lower than $\pm 2.5 \%$, while the dashed line encloses the $10 \mathrm{~cm} \times 10 \mathrm{~cm}$ substrate area.

Fig. 3 Deposition rate $\mathrm{R}_{\mathrm{d}}$ as a function of the Raman crystallinity factor $X_{\mathrm{c}}$ for four different deposited series.

Fig. 4 Depiction of the Si-O-Si SMs and the hydride SMs for nc-Si:H material close to the crystalline transition for the four different deposition series. The thicker lines correspond to as deposited material and the thinner ones to the same samples after 12 days of exposure to ambient air. 
Fig. 1

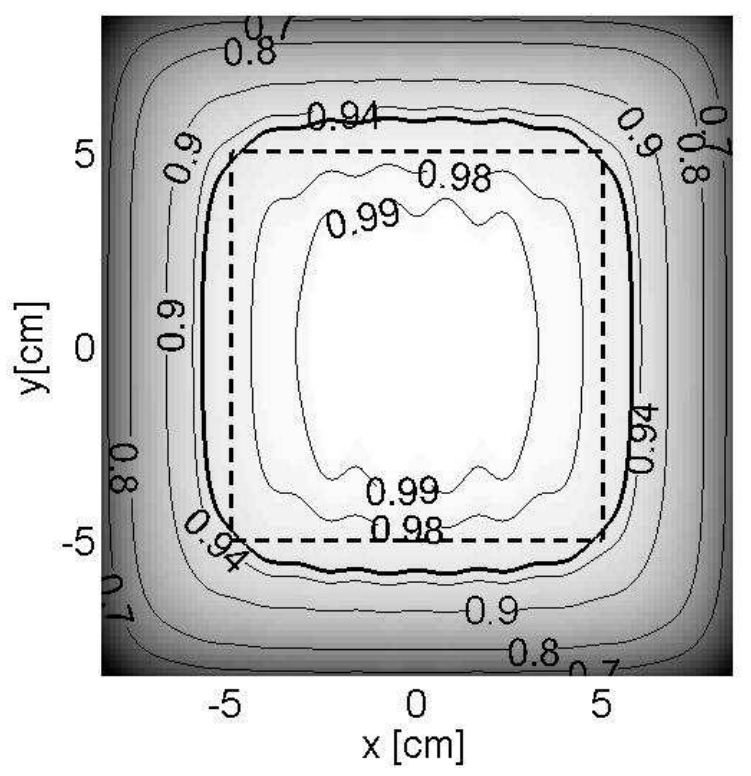

Fig. 2

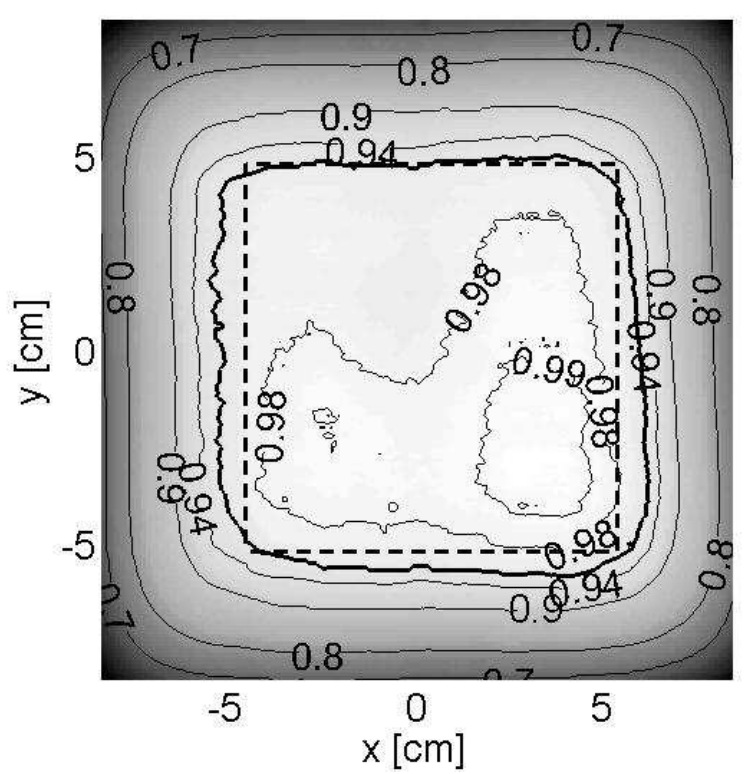


Fig. 3

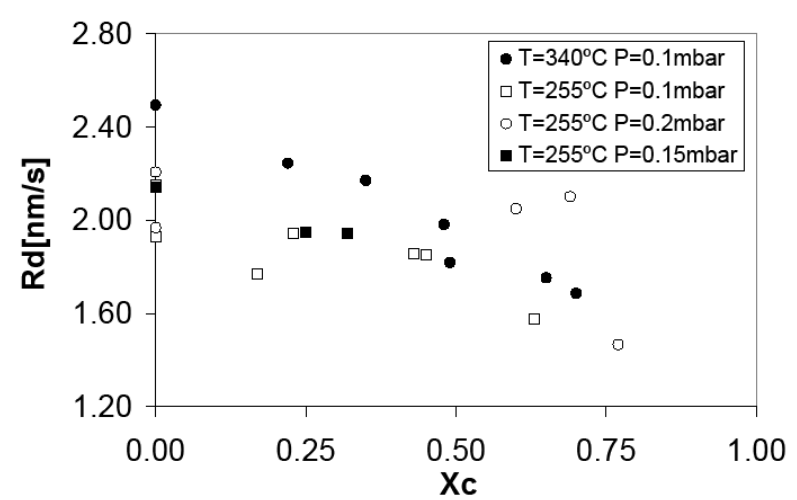

Fig. 4

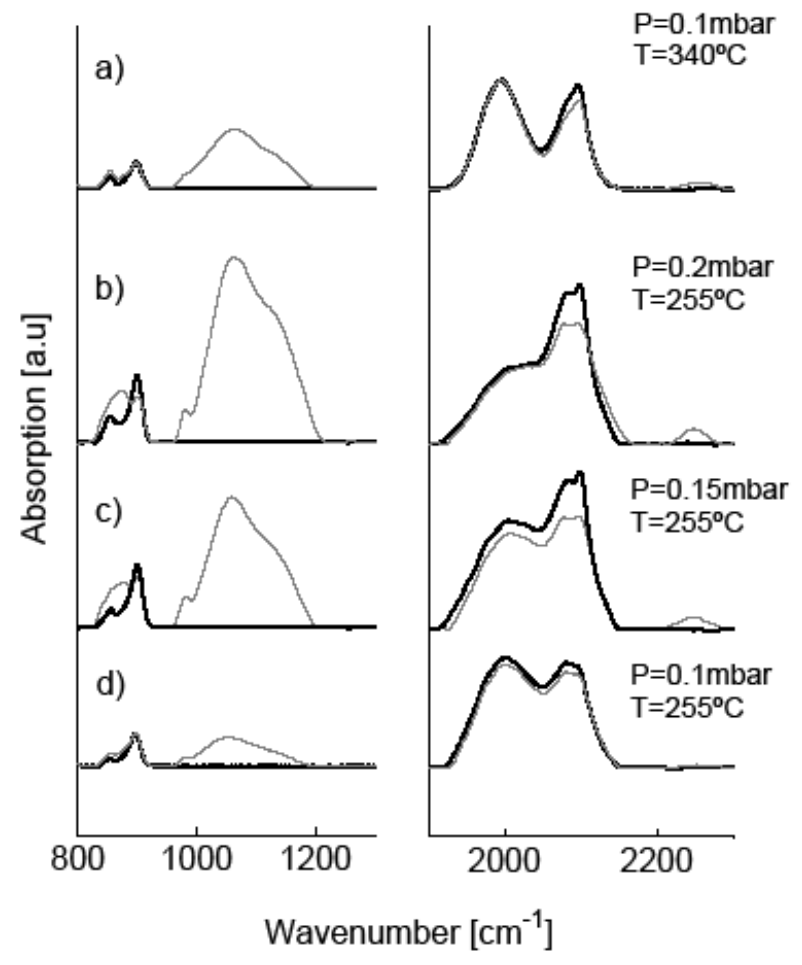

